\title{
Correction to: To appease or to repress: how dictators use economic dynamics to increase their regime longevity
}

\author{
Merel Harrijvan ${ }^{1}$ (D) Maartje Weerdesteijn ${ }^{1}$ \\ Published online: 3 September 2020 \\ (C) Springer Nature B.V. 2020
}

\section{Correction to: Crime, Law and Social Change https://doi.org/10.1007/s10611-020-09911-4}

The original version of this article unfortunately contained a mistake. The Fig. 1 caption was incorrect and the figure was put into the wrong position within the text. The correct caption is given below and the original article has been corrected.

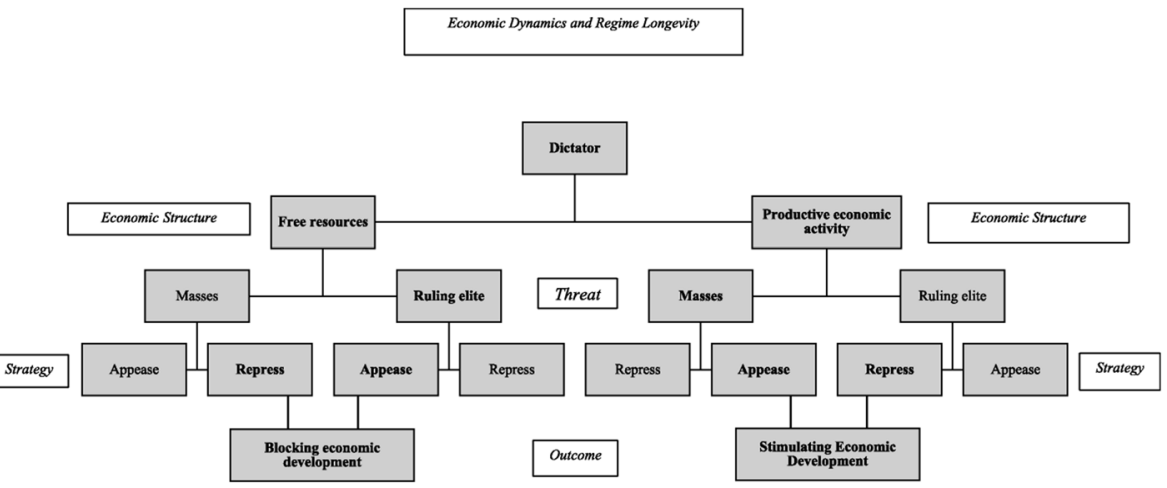

Fig. 1 The analytical framework

Publisher's note Springer Nature remains neutral with regard to jurisdictional claims in published maps and institutional affiliations.

The online version of the original article can be found at https://doi.org/10.1007/s10611-020-09911-4

Merel Harrijvan

merel.harrijvan@cicj.org

Maartje Weerdesteijn

m.weerdesteijn@vu.nl

1 Center for International Criminal Justice, VU University Amsterdam, Amsterdam, Netherlands 